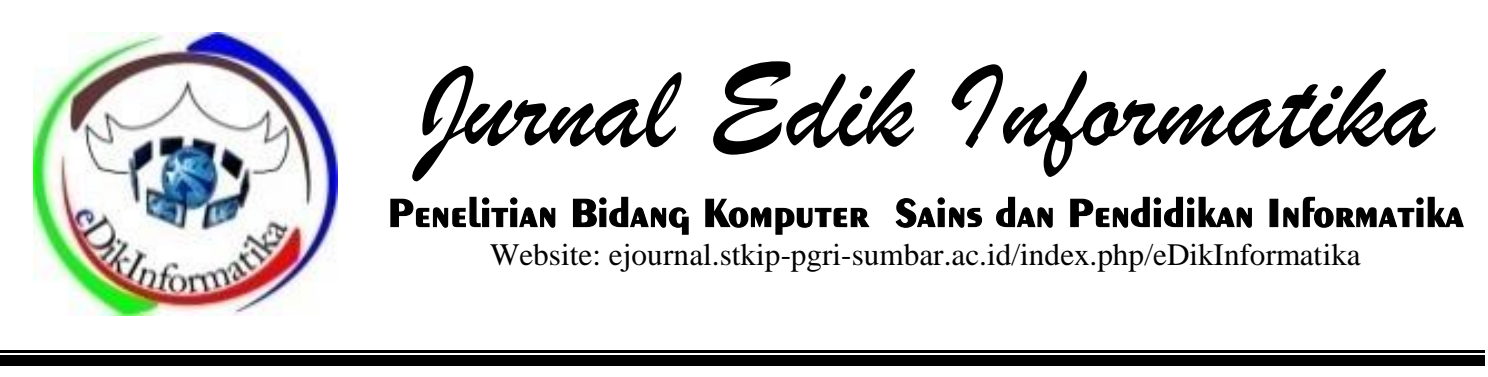

\title{
APLIKASI PENYUSUNAN IKATAN KIMIA BERBASIS ANDROID SEBAGAI MEDIA PEMBELAJARAN
}

\author{
Muhammad Zulfadhilah', Nur Hidayah ${ }^{2}$ \\ 1.2Universitas Sari Mulia \\ zulfadhilah@unism.ac.id
}

\section{INFO ARTIKEL}

Diterima:

18 Oktober 2019

Direview:

05 November 2019

Disetujui:

26 November 2019

\begin{tabular}{l}
\hline Keywords: \\
\hline Voting, e-voting, \\
pengembangan sistem, \\
berbasis web.
\end{tabular}

\begin{abstract}
Education in the future will be influenced by information networks that allow interaction and collaboration. Technological innovations in the field of education have increasingly advanced, learning methods using technology from a software is currently growing. Mobile-based software is one of the media in helping the educational process in the current digital era. In this paper we will discuss making an application as a learning medium. The method used in making this application uses the system development model SDLC (System Development Lite Cyle). The SDLC model that will be used is a systematic, sequential waterfall in building software. The general stages in the waterfall method are requirements analysis, system design, system implementation, and finally system testing. Making this Android-based software using data that already exists in the main and supporting literature. This application contains chemical periodic table information and a chemical bond calculator. The results of making this application are very helpful for students in understanding chemical learning, especially in chemical bonding material.
\end{abstract}

\section{PENDAHULUAN}

Proses pembelajaran adalah proses aktif, karena pengetahuan terbentuk dari dalam subyek belajar. Untuk membantu perkembangan kognitif anak, kepadanya perlu diciptakan suatu kondisi belajar yang memungkinkan anak belajar sendiri, misalnya melakukan percobaan, manipulasi simbol-simbol, mengajukan pertanyaan dan mencari jawaban sendiri, membandingkan penemuan sendiri dengan penemuan temannya. Saat belajar perlu diciptakan suasana yang memungkinkan terjadinya interaksi diantara subyek belajar (Sunarto, Sumarni, \& Suci, 2011). Mason R. berpendapat bahwa Pendidikan pada masa yang akan datang ditentukan oleh jaringan informasi yang memungkinkan berinteraksi dan kolaborasi, bukannya gedung sekolah. Tony Bates menyatakan bahwa teknologi dapat meningkatkan 
kualitas dan jangkauan bila digunakan secara bijak dalam Pendidikan dan latihan, karena teknolgi dan Pendidikan mempunyai arti yang sangat penting bagi kesejahteraan ekonomi. Serta pendapat dari Alisjahbana yang mengemukakan bahwa pendekatan Pendidikan dan pelatihan nantinya akan bersifat just on time. Teknik pengajaran baru akan bersifat dua arah, yaitu kolaboratif dan interdisipliner (Sutabri, 2014).

Tuntutan perkembangan teknologi informasi ini merupakan sebuah tuntutan dan usaha dalam peningkatan mutu pendidikan pada umumnya dan peningkatan sistem pembelajaran dewasa ini. maka dalam makalah ini akan mencoba membahas tentang sistem pembelajarn berbasis tekonologi informasi dan komunikasi (Andiani, 2015).

Berdasarkan uraian di atas maka sebagai langkah awal pada artikel ini akan membahas sebuah aplikasi penyusunan ikatan kimia dengan berbasis Android yang mampu memberikan dan menyajikan informasi mengenai informasi kimia. Aplikasi ini diharapkan dapat menjadi inovasi sehingga memudahkan dalam pembelajaran materi kimia khususnya yang berkaitan dengan ikatan kimia.

\section{TINJAUAN PUSTAKA}

Pendidikan adalah segala daya upaya dan semua usaha untuk membuat masyarakat dapat mengembangkan potensi peserta didik agar memiliki kekuatan spiritual keagamaan, pengendalian diri, berkepribadian, memiliki kecerdasan, berakhlak mulia, serta memiliki keterampilan yang diperlukan sebagai anggota masyarakat dan warga negara (Rini, 2017).
Ilmu Kimia merupakan salah satu cabang Ilmu Pengetahuan Alam yang sangat penting dan memiliki keterkaitan langsung serta memberi kontribusi dalam pengembangan ilmu lainnya. Akan tetapi sampai saat ini ilmu kimia masih kurang diminati, khususnya bagi mahasiswa/siswa SMA karena menganggap mata pelajaran ini sebagai mata pelajaran yang susah sebab terlalu banyak menggunakan rumus dan materinya banyak mengandung konsepkonsep yang abstrak. Persepsi ini mengakibatkan pengetahuan dasar ilmu kimia yang dimiliki oleh mahasiswa ketika melanjutkan studi pada tingkat perguruan tinggi menjadi sangat minim, sehingga berdampak pada kurangya kemampuan penguasaan konsep ilmu kimia (Allo, Side, Permanasari, \& Setiabudi, 2010).

Kajian ilmu kimia meliputi struktur materi, komposisi, sifat, perubahannya serta energi yang terlibat dalam perubahan tersebut. Beberapa konsep dalam kajian kimia menimbulkan kesulitan dan kesalahan bagi pembelajar karena sebagian besar berkaitan dengan konsep abstrak (Solfarina, 2012).

Aplikasi Mobile adalah perangkat lunak yang berjalan pada perangkat mobile seperti smartphone atau tablet PC. Aplikasi mobile juga dikenal sebagai aplikasi yang dapat diunduh dan memiliki fungsi tertentu sehingga menambah fungsionalitas dari perangkat mobile itu sendiri. Untuk mendapatkan mobile application yang diinginkan, pengguna dapat mengunduhnya melalui situs tertentu sesuai dengan sistem operasi yang dimiliki. Google Play dan iTunes merupakan beberapa contoh dari situs yang menyediakan beragam aplikasi bagi pengguna Android dan iOS untuk 
mengunduh aplikasi yang diinginkan (Irsan, 2015).

Aplikasi mobile dapat dengan mudah melakukan berbagai macam aktifitas mulai dari hiburan, berjualan, belajar, mengerjakan pekerjaan kantor, browsing dan lain sebagainya. Pemanfaatan aplikasi mobile untuk hiburan paling banyak digemari oleh hampir $70 \%$ pengguna telepon seluler, karena dengan memanfaatkan adanya fitur game, music player, sampai video player membuat kita menjadi semakin mudah menikmati hiburan kapan saja dan dimanapun (Farizah, Nur \& Kosidin, 2016).

\section{METODE PENELITIAN}

Metode penelitian yang digunakan dalam penelitian ini menggunakan model pengembangan sistem SDLC (System Development Lite Cyle) atau daur hidup pengembangan sistem. Model SDLC yang akan digunakan adalah metode waterfall yang bersifat sistematis, berurutan dalam membangun perangkat lunak dari penelitian ini. Model ini seperti pada gambar 1 berikut :
1. Analisa Kebutuhan

Tahap analisis merupakan tahap yang digunakan untuk mengetahui keperluan pembangunan sebuah sistem. Pada tahap ini akan dilakukan analisis data yang akan diambil untuk keperluan sistem.

2. Desain Sistem

Desian sistem terdiri dari perancangan database dan perancangan interface. Tahap ini juga bertujuan untuk memberikan gambaran mengenai alur kerja sistem. Perancangan database nantinya akan dilakukan dengan konseptual, logika dan fisik. Perancangan interface dilakukan untuk merancang tampilan yang userfrendly sedangkan untuk perancangan proses nantinya menggunakan activity diagram.

3. Implementasi Sistem

Implementasi sistem merupakan pengimplementasian dalam bentuk program atau pengkodingan untuk membuat Rancang Bangun Aplikasi Penyusunan Ikatan Kimia Berbasis Android. Bahasa pemrograman yang digunakan adalah Java dan menggunakan Database MySql.

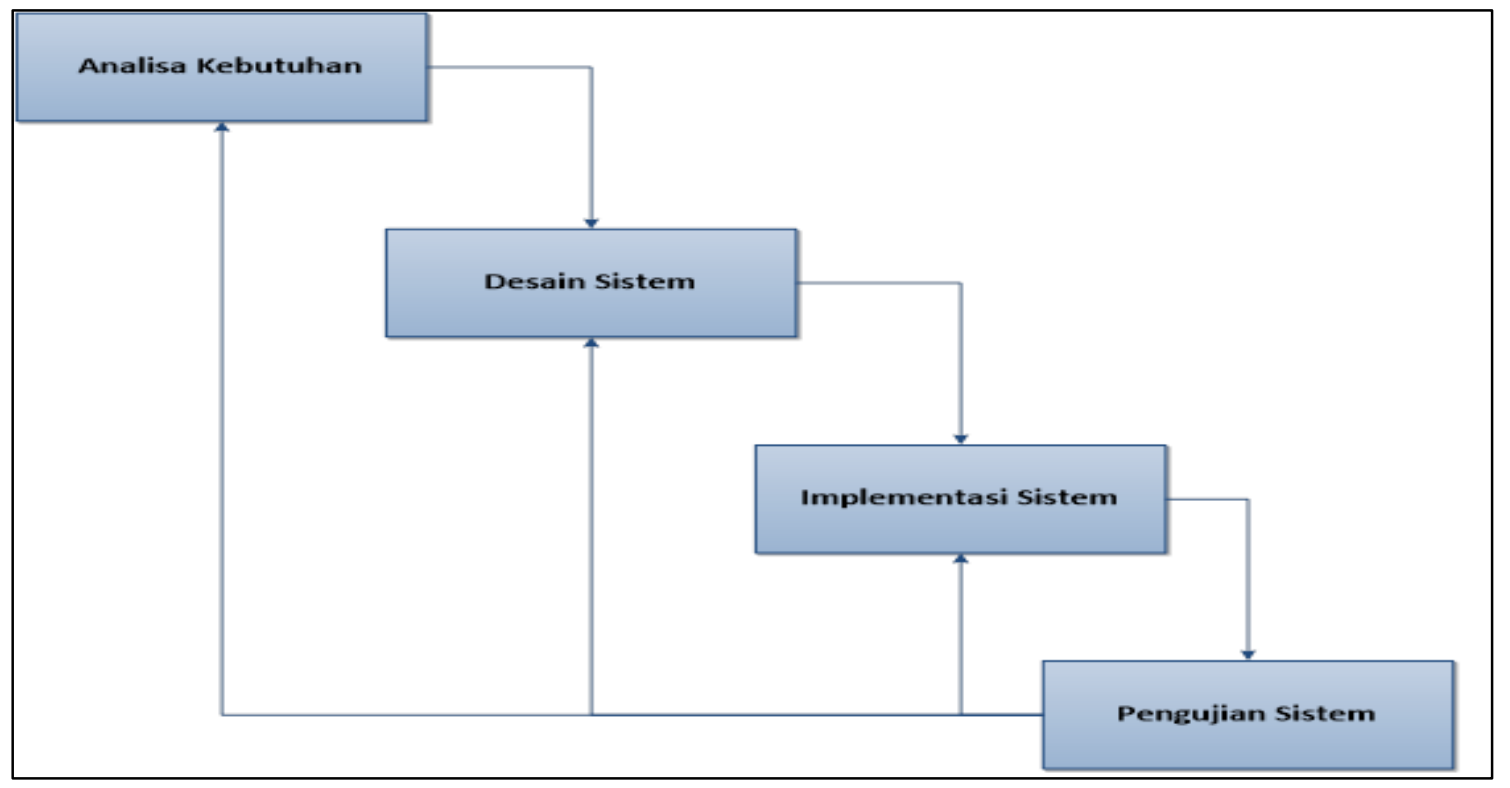

Gambar 1. Metode Waterfaal 


\section{Pengujian Sistem}

Pengujian dilakukan untuk menghindari kesalahan dari sistem yang dibuat. Apabila terjadi kesalahan, maka sistem akan diperbaiki kembali sampai hasil proses sesuai dengan apa yang diharapkan. Aplikasi tersebut diuji dengan metode black box, yang menguji dari segi fungsional dari tiap komponen tampilan program yang memastikan keluaran yang dihasilkan sesuaikan dengan yang diinginkan. Pada tahapan ini peneliti yang berhubungan dalam bidang Kimia akan ikut serta melakukan pengujian, agar keluaran dari hasil aplikasi ini sesuai dengan yang diharapkan kedua peneliti dan sesuai dengan kebutuhan responden nantinya.

\section{HASIL DAN PEMBAHASAN}

Pembuatan aplikasi ini tidak lepas dari peran siswa yang mengisi kuesioner sebelum pemakaian aplikasi. Kuesioner yang dibagi kepada 34 orang siswa pada sekolah yang berbeda-beda. Pengumpulan data awal kepada siswa ini bertujuan untuk mengetahui apakah para siswa sudah menggunakan aplikasi-aplikasi sebagai media pembelajaran selain dari media cetak yang sudah ada.
Berdasarkan hasil kuesioner (gambar 2) yang dibagi menyatakan bahwa penggunaan aplikasi berbasis android yang dipakai sebagai media belajar masih rendah. Berdasarkan data yang didapat, siswa masih menggunakan media cetak sebagai literatur utama dalam pembelajaran, terlihat ada $88 \%$ siswa yang masih menggunakan media cetak sebagai literatur sedangkan $12 \%$ lainnya sudah menggunakan media non-cetak sebagai media pembelajaran. Data yang didapat juga memperlihaatikan bahwa ada siswa yang sudah menggunakan media online dalam pembelajaran sebanyak $34 \%$, media online disini maksudnya adalah menggunakan Internet dalam pmencari informasi tambahan, sedangkan $66 \%$ masih menggunakan media offline dalam pembelajaran. Selain itu data yang didapat dari hasil kuesioner tersebut memperlihatkan pada pertanyaan terkait penggunaan aplikasi Android sebagai media pembelajaran hanya ada sekitar $35 \%$ yang menggunakan aplikasi Android sebagai media pembelajaran, sedangkan $65 \%$ masih belum memakai aplikasi berbasis Android sebagai media pembelajaran Kimia.

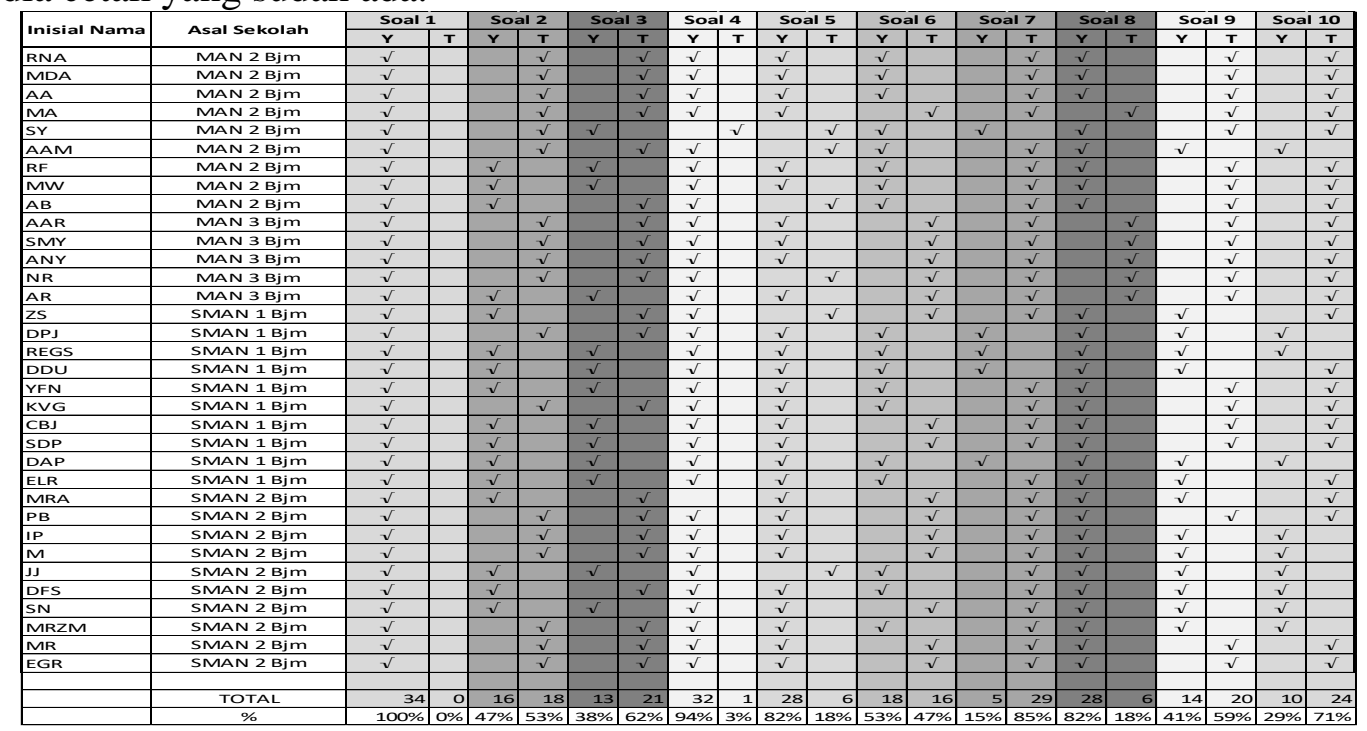

Gambar 2. Data Kuesioner Siswa 
Aplikasi Android ini mempunyai beberapa fitur yang bisa digunakan oleh siswa nantinya. Fitur-fitur tersebut adalah Tabel Periodik dan kalkulator Kimia, pada table periodik akan berisi tentang informasi unsur-unsur kimia, sedangkan untuk kalkulator kimia akan memberikan informasi singkat tentang unsur yang telah digabungkan.
Pada tampilan awal aplikasi terlihat ada beberapa menu pilihan, yaitu table periodic, kalkulator kimia, tentang aplikasi dan keluar. Setiap menu yang dipilih akan menampilkan tampilan yang berbeda pula, kecuali pada menu keluar yang jika dipilih akan mengeluarkan aplikasi tersebut. Tampilan awal pada aplikasi yang telah dibuat dan dinamakan siChemy dapat dilihat pada gambar 3 .

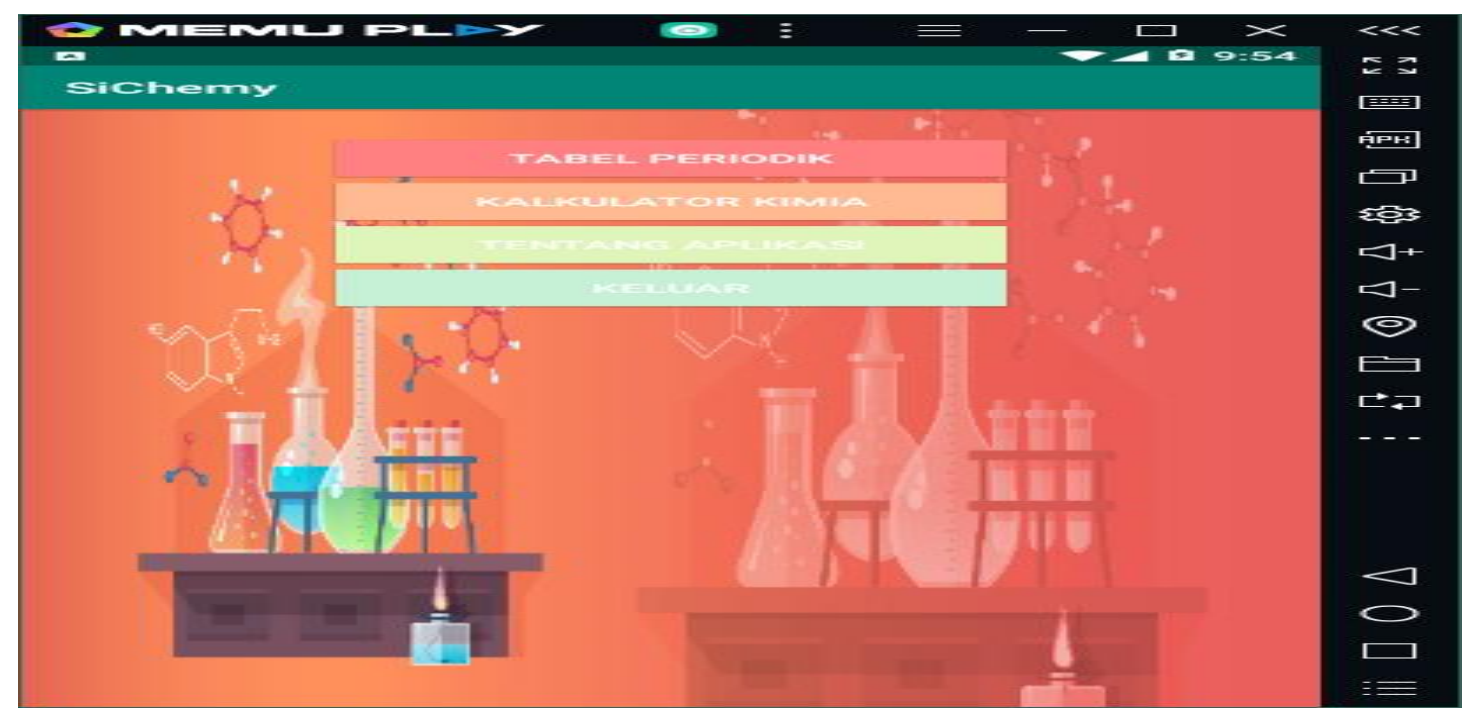

Gambar 1. Tampilan Awal Aplikasi

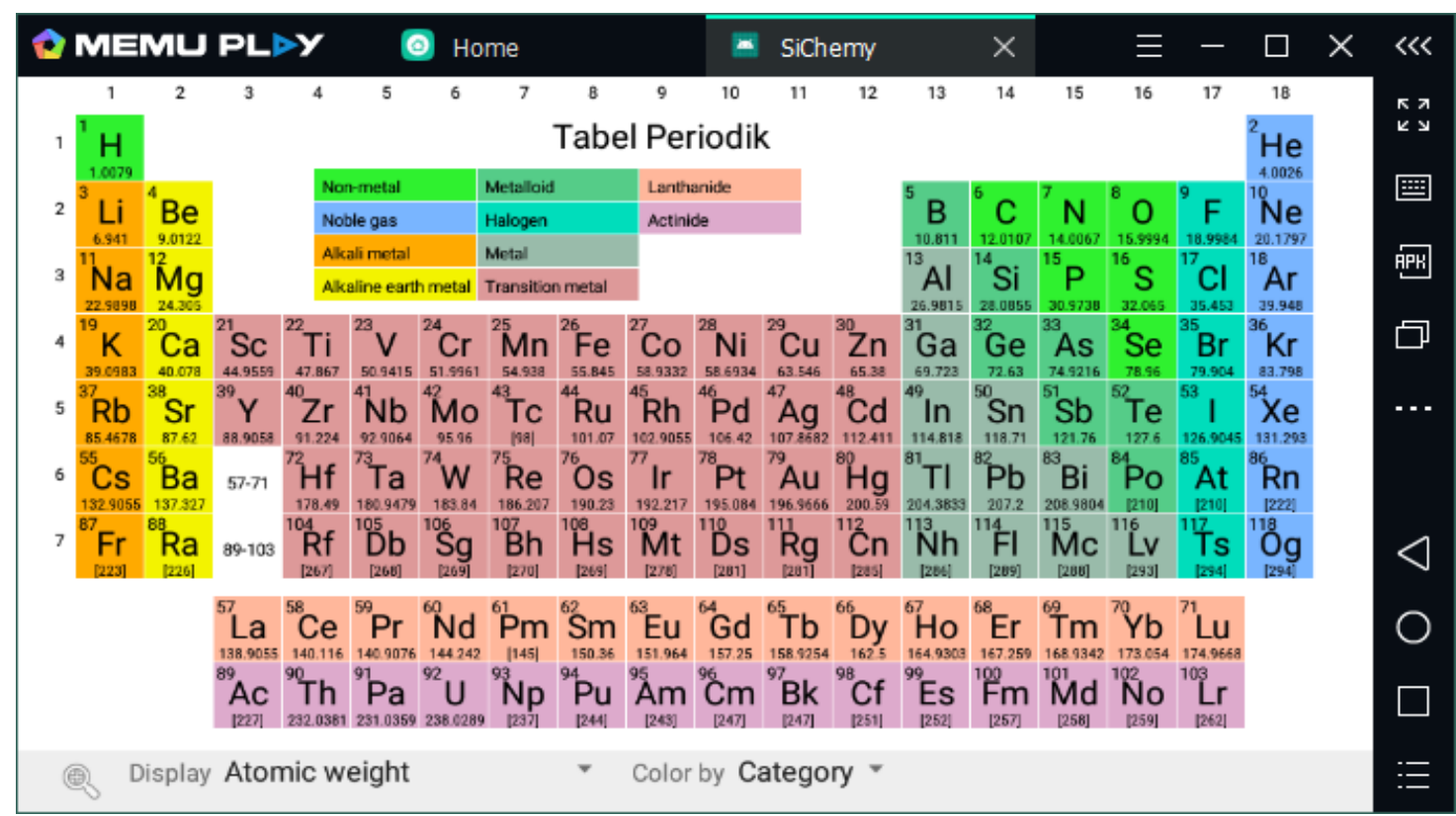

Gambar 4. Tabel Periodik 


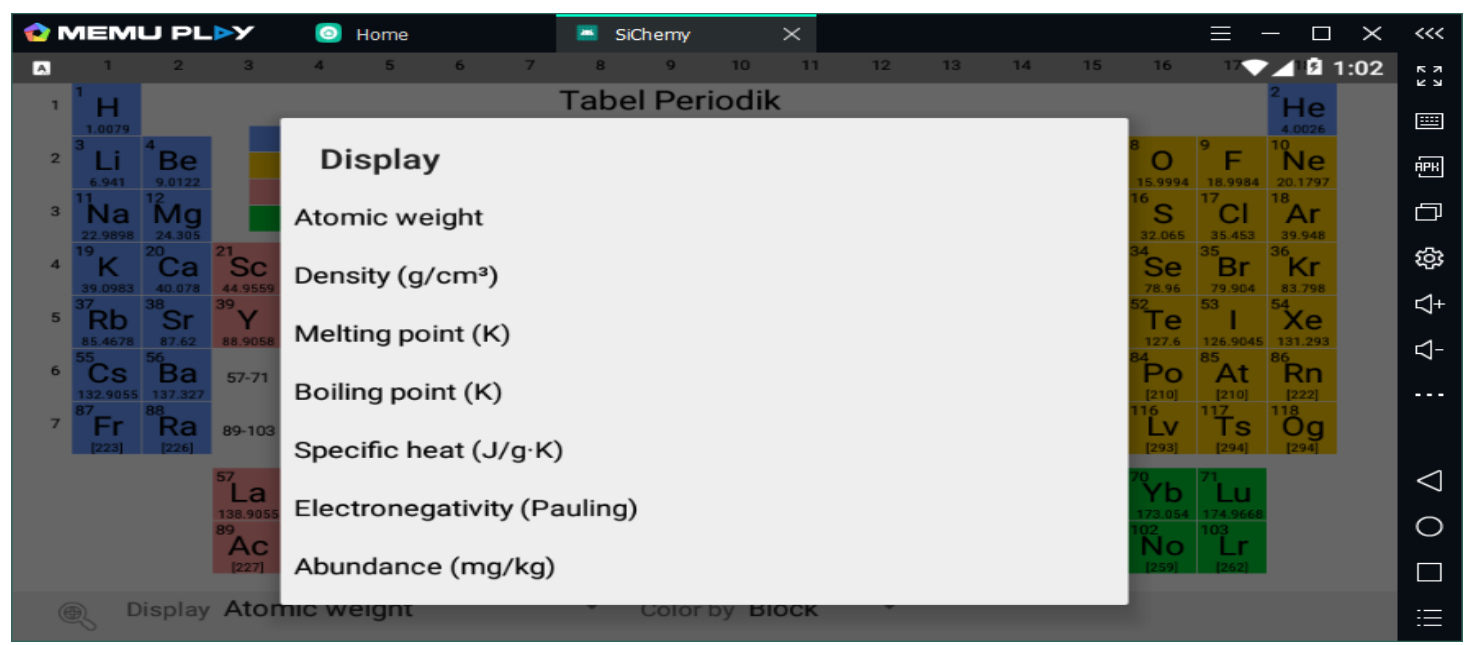

Gambar 5. Pengaturan Tabel Periodik

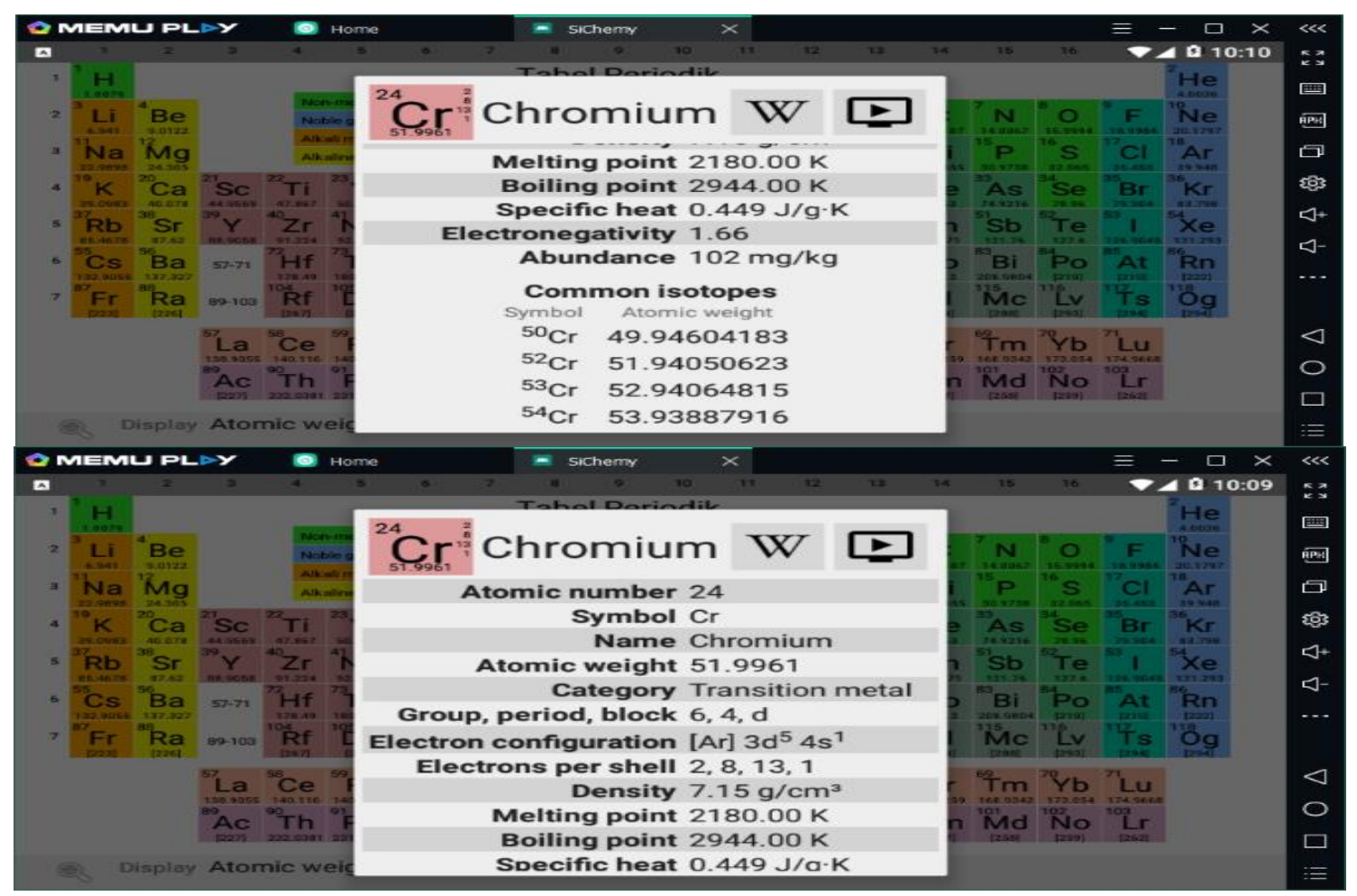

Gambar 6 Detail Unsur

Menu tabel Periodik akan mengantarkan pengguna ke halaman table periodic (gambar 4) yang mana pada menu ini, unsur bisa di-sort sesuai dengan kebutuhan, ada yang berdasarkan kategori unsur dan ada yang sesuai block. Selain itu ada juga pilihan tampilan berdasarkan berat atom, titik didih, dan lain sebagainya (Gambar 5).

Pada tabel periodik (Gambar 4) setiap unsur yang dipilih akan menampilkan detail informasi unsur tersebut, seperti contoh pada gambar 6 . Pada gambar 6 juga terlihat ada pilihan menuju Wikipedia untuk detail unsur lainnya dan ke Youtube untuk melihat video unsur tersebut. Diharapkan dengan adanya menu tersbut, siswa ataupun pengguna lainnya bisa lebih memahami mengenai unsur kimia yang ada di table periodik. 


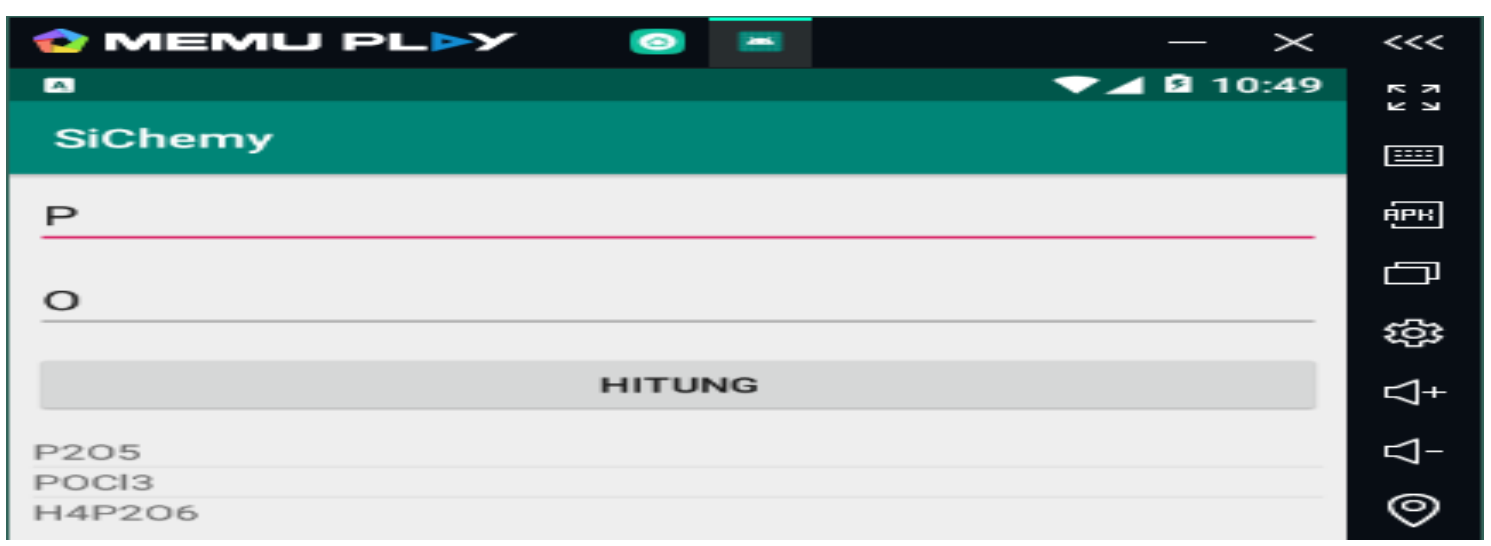

Gambar 7 Kalkulator Kimia

Pada gambar 7 merupakan tampilan dari menu kalkulator kimia. Unsur dimasukkan pada aplikasi untuk melihat kemungkinan terbentuknya ikatan dari unsur yang dimaksud. Setelah itu akan muncul kemungkinan-kemungkinan ikatan yang akan terbentuk, dan bisa dilihat detail ikatan tersebut dengan memilih salah satu dari beberapa yang muncul pada tampilan aplikasi. Detail ikatan yang terbentuk bisa dilihat dengan memilih salah satu dari hasil penggabungan unsur, seperti pada gambar 8.

\section{KESIMPULAN DAN SARAN}

Pembuatan aplikasi ikatan kimia berbasis Android berhasil dibuat berdasarkan hasil kuesioner yang mana pemakaian aplikasi berbasis Android sebagai media pembelajaran hanya berkisar $35 \%$, sedangkan $65 \%$ sisanya masih belum menggunakan aplikasi berbasis Android sebagai media pembelajaran. Pada aplikasi ini memuat beberapa menu pilihan untuk digunakan oleh siswa atau user lainnya, yaitu tabel periodik yang akan menampilkan tabel periodik kimia serta detail dari unsurnya dan kalkulator kimia yang merupakan fitur unggulan dari aplikasi serupa.

Penelitian ini jauh dari sempurna, diharapkan kedepannya aka nada aplikasi yang lebih baik dari aplikasi ini. penulis berharap penelitian ini bisa berguna sebagai media pembelajaran bagi siswa, khususnya dalam materi kimia dasar.

\section{DAFTAR PUSTAKA}

Allo, E. L., Side, S., Permanasari, A., \& Setiabudi, A. (2010). Integrasi Model Pembelajaran Kimia Berbasis Teknologi Informasi dan Hiperteks. Jurnal Chemica, 11(1), 22-27.

Andiani, T. (2015). Sistem Pembelajaran Berbasis Teknologi Informasi dan Komunikasi. Sosial Budaya: Media Komunikasi Ilmu-Ilmu Sosial Dan Budaya, 12(1).

Farizah, Nur, R., \& Kosidin. (2016). Pemodelan aplikasi mobile reminder berbasis android. Seminar Nasional Teknologi Informasi Dan Komunikas, 2016(Sentika), 18-19.

Irsan, M. (2015). Rancang Bangun Aplikasi Mobile Notifikasi Berbasis Android untuk Mendukung Kinerja di Instansi Pemerintahan. 1(1). Retrieved from http://jurnal.untan.ac.id/index.php/ju stin/article/view/9984/9752

Plungsombat, K., Jearapan, P., Pittayanukit, T., \& Wongsawang, D. (2017). Pelement: A periodic table game for elements learning. 6th ICT International Student Project 
Conference: Elevating Community Through ICT, ICT-ISPC 2017, 2017January, $1-4$. https://doi.org/10.1109/ICTISPC.2017.8075296

Rini, Y. S. (2017). Pendidikan : Hakekat, Tujuan, dan Proses. 91, 399-404.

Solfarina. (2012). Imporovement of Chemical Bonding Concept Understanding on Prospective Teachers Based E-Learning. Jurnal Chemica, 13(2), 1-10.

Sunarto, W., Sumarni, W., \& Suci, E. (2011). Hasil Belajar Kimia Siswa Dengan Model Pembelajaran Metode Think-Pair-Share Dan Metode
Ekspositori. Jurnal Inovasi Pendidikan Kimia, 2(1), 244-249.

Sutabri, T. (2014). Pengantar Teknologi Informasi (1st ed.; A. Sahala \& S. Wibowo, eds.). Yogyakarta: CV. Andi Offset.

Troetsth, A., Molina, J., \& Garita, C. (2015). A Prototype of a Virtual World with Collaborative Games for the Study of the Periodic Table of Elements. IEEE Latin America Transactions, 13(2), 476-482. https://doi.org/10.1109/TLA.2015.7 055567 